\title{
A Case of Neuromyelitis Optica Presenting with Intractable Hiccups and Vomiting: Area Postrema Syndrome
}

\author{
Dirençli Kusma ve Hıçkırıkla Başlayan Bir Nöromiyelitis Optika Olgusu:
} Area Postrema Sendromu

\author{
Derya Kaya1, Egemen İdiman ${ }^{2}$, Fethi İdiman², Onur Bulut ${ }^{2}$, Nuri Karabay 3 \\ ${ }^{1}$ Dokuz Eylül University Faculty of Medicine, Division of Geriatrics, İzmir, Turkey \\ 2Dokuz Eylül University Faculty of Medicine, Department of Neurology, İzmir, Turkey \\ ${ }^{3}$ Dokuz Eylül University Faculty of Medicine, Department of Radiology, İzmir, Turkey
}

Keywords: Area postrema syndrome, neuromyelitis optica, neuromyelitis optica spectrum disorders

Anahtar Kelimeler: Area postrema sendromu, neuromyelitis optika, nöromiyelitis optika spektrum hastalıkları

\section{Introduction}

A woman aged 32 years was admitted to our clinic after she visited a gastroenterology center with symptoms of intractable hiccups and vomiting; no gastroenterologic pathology was found to explain her symptoms after a detailed examination. There were no other abnormalities in the patient's history except for intractable hiccups and vomiting that had lasted for about one month. A neurologic examination revealed no significant neuropathologic findings except hypoesthesia of the left half of the face in dermatomes of $2^{\text {nd }}$ and $3^{\text {rd }}$ branches of cranial nerve $\mathrm{V}$, reduced deep sensation on the right side, and suspicious dysmetria on the left side of the body. Complete blood count, biochemical studies, C3, C4, C-reactive protein, sedimentation, electrolytes $(\mathrm{Na}, \mathrm{K}, \mathrm{Cl})$ were within normal limits and vasculitic/immunologic tests were negative. Serum neuromyelitis optica-immunoglobulin $\mathrm{G}$ (NMO-IgG) was negative. A heterogeneous hyperintensity that extended from the medulla oblongata to the level of $\mathrm{C} 3$ and volume increase in the medulla oblongata and upper cervical region were observed on contrast-enhanced T2-weighted magnetic resonance images (MRI). Heterogeneous contrast enhancement was seen at the medulla oblongata and C1-C2 levels on post-contrast images (Figures 1a, b, c). MR spectroscopy was performed for the radiologic differential diagnosis of the medulla oblongata to determine whether there was tumor, inflammation, or ischemia; it was evaluated as inflammatory.
The patient underwent lumbar puncture and no oligoclonal bands were detected in the patient's cerebrospinal fluid. The IgG index was found as 0.63. One gram per day iv. methylprednisolone was administered for 10 days. The patient's symptoms were completely recovered and she was discharged and requested to return for follow-up examinations.

One month later, the patient was admitted with symptoms of a tingling sensation that started from her back, spread up to her neck, and caused contractions in her arms at the same time. With the exception of Lhermitte's sign, the findings of a neurologic examination were within normal limits. Repeat cranial, cervical, and thoracic MRI revealed no new lesions; regression and loss of contrast enhancement was seen in the previous lesion that extended to the C2-C3 level, starting from the medulla oblongata. Serum samples were taken again for NMO-IgG analysis and NMO-IgG were found positive this time. Three $\mathrm{mg} / \mathrm{day}$ azathioprine and 20 mg prednisolone tablet treatment was initiated with a diagnosis of NMO.

Although the presented case showed no involvement of two basic areas, optic nerve and spinal cord involvement, which are required according to the 2006 Wingerchuk criteria (1), the patient was diagnosed as having NMO spectrum disorders in accordance with the 2015 NMO criteria (2) because she was NMO-IgG positive and had one core clinical characteristic, area postrema involvement. Rapid and accurate diagnosis of patients 

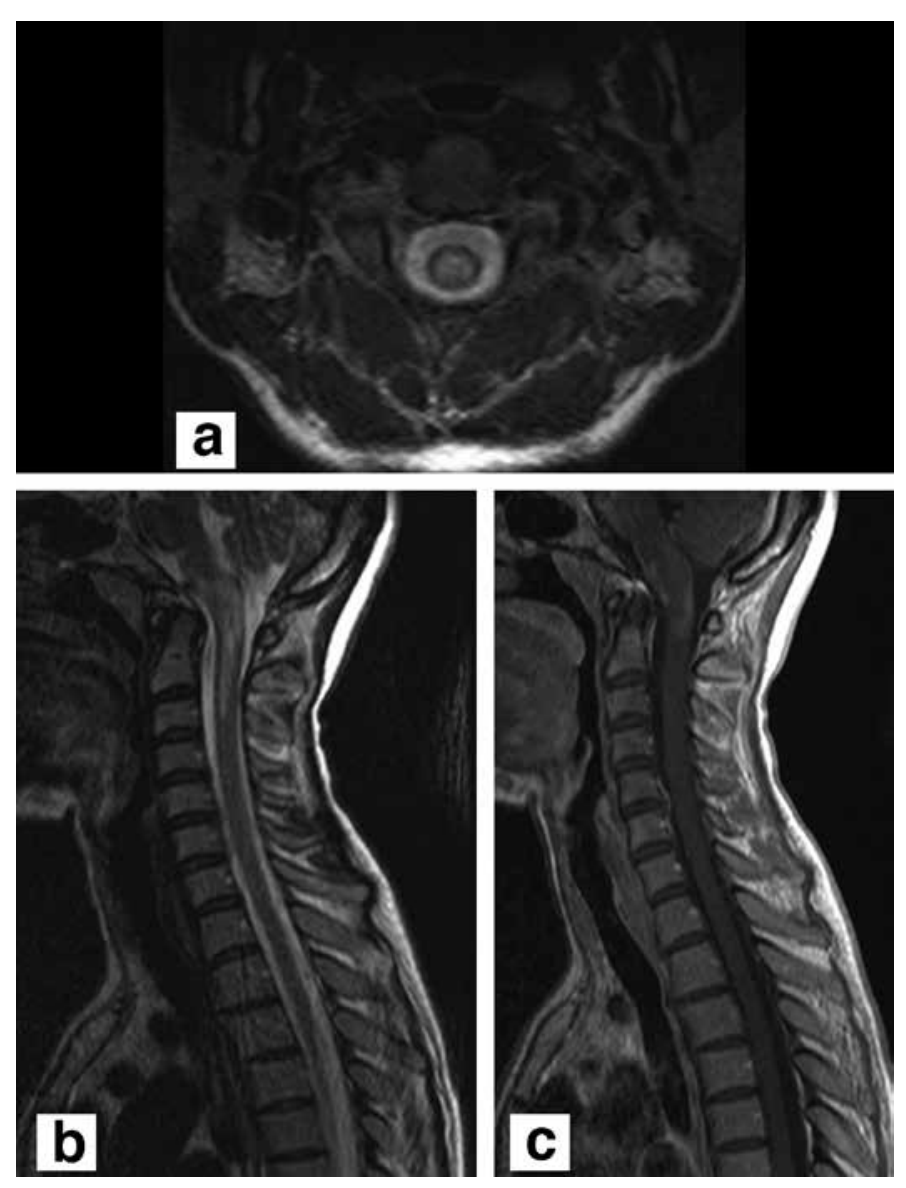

Figure 1. Brain and cervical magnetic resonance images of the patient. Centrally located hyperintense areas of demyelination extending from medulla oblongata to spinal cord (up to C3 vertebra level) and causing a slight expansion in the spinal cord on T2-weighted axial (a) and sagittal (b) magnetic resonance images. Heterogeneous contrast enhancement in the areas of demyelination on post-contrast sagittal T1-weighted magnetic resonance images (c) with atypical onset will ensure initiation of early treatment, prevention of future attacks, and permanent disability caused by the attacks.

\section{Etbics}

Informed Consent: Informed consent form was filled out by the case. Peer-review: Internal peer-reviewed.

\section{Authorship Contributions}

Surgical and Medical Practices: Egemen Idiman, Fethi Idiman, Concept: Egemen Idiman, Design: Derya Kaya, Egemen İdiman, Data Collection or Processing: Onur Bulut, Derya Kaya, Nuri Karabay, Analysis or Interpretation: Derya Kaya, Egemen Idiman, Fethi İdiman, Literature Search: Onur Bulut, Derya Kaya, Writing: Derya Kaya, Egemen İdiman.

Conflict of Interest: No conflict of interest was declared by the authors.

Financial Disclosure: The authors declared that this study has received no financial support.

\section{References}

1. Wingerchuk DM, Lennon VA, Pittock SJ, Lucchinetti CF, Weinshenker BG. Revised diagnostic criteria for neuromyelitis optica. Neurology 2006;66:1485-1489.

2. Wingerchuk DM, Banwell B, Bennett JL, Cabre P, Carroll W, Chitnis T, de Seze J, Fujihara K, Greenberg B, Jacob A, Jarius S, Lana-Peixoto M, Levy M, Simon JH, Tenembaum S, Traboulsee AL, Waters P, Wellik KE, Weinshenker BG. International consensus diagnostic criteria for neuromyelitis optica spectrum disorders. Neurology 2015;85:177-189. 